
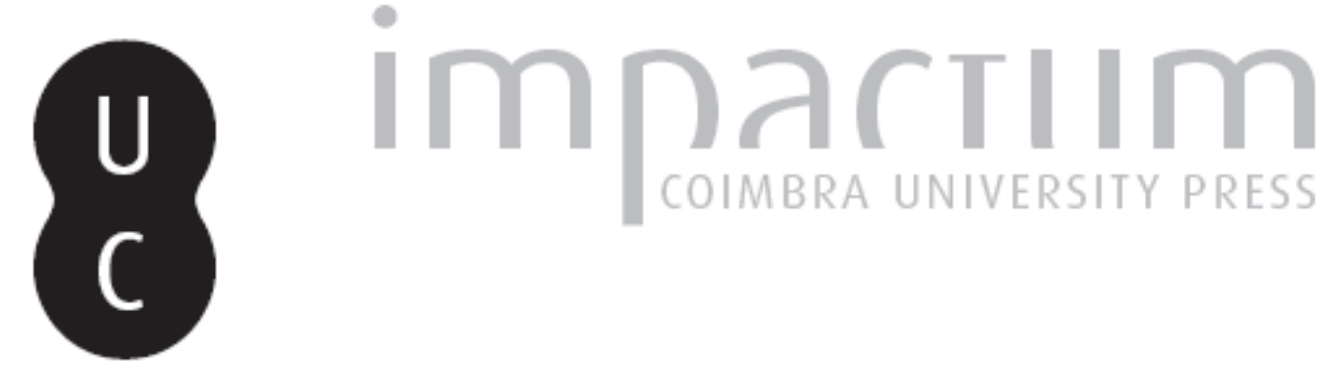

\title{
[Recensão a] NOGALES BASARRATE (Trinidad) e SÁNCHEZ-PALENCIA (Francisco Javier) (coord.), El Circo en Hispania Romana
}

\author{
Autor(es): Barata, Maria Filomena
}

Publicado por: Faculdade de Letras da Universidade de Coimbra

URL persistente:

URI:http://hdl.handle.net/10316.2/37693

DOI:

DOI:http://dx.doi.org/10.14195/1647-8657_42_11

Accessed : $\quad$ 26-Apr-2023 10:33:31

A navegação consulta e descarregamento dos títulos inseridos nas Bibliotecas Digitais UC Digitalis, UC Pombalina e UC Impactum, pressupõem a aceitação plena e sem reservas dos Termos e Condições de Uso destas Bibliotecas Digitais, disponíveis em https://digitalis.uc.pt/pt-pt/termos.

Conforme exposto nos referidos Termos e Condições de Uso, o descarregamento de títulos de acesso restrito requer uma licença válida de autorização devendo o utilizador aceder ao(s) documento(s) a partir de um endereço de IP da instituição detentora da supramencionada licença.

Ao utilizador é apenas permitido o descarregamento para uso pessoal, pelo que o emprego do(s) título(s) descarregado(s) para outro fim, designadamente comercial, carece de autorização do respetivo autor ou editor da obra.

Na medida em que todas as obras da UC Digitalis se encontram protegidas pelo Código do Direito de Autor e Direitos Conexos e demais legislação aplicável, toda a cópia, parcial ou total, deste documento, nos casos em que é legalmente admitida, deverá conter ou fazer-se acompanhar por este aviso.

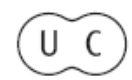


CONIMBRIGA

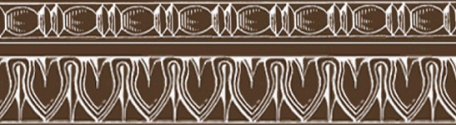

NSTITUTO DE ARQUEOLOGI

I

VOLUME XLII - 2003

A C U L D

UNIVERSIDADE DE COIMBR 
constitui um ponto de partida para novos trabalhos - pois, como diz Desiderio Vaquerizo, o programa de investigação do Seminário de Arqueologia de Córdova não se encerra aqui, mas aqui recomeça ou daqui prossegue.

JORGE DE ALARCÃo

Nogales BasarRate (Trinidad) e SÁnchez-Palencia (Francisco Javier) (coord.), El Circo en Hispania Romana. Ministerio de Educación, Cultura y Deporte de Espanha, com a colaboração da Dirección General de Patrimonio de la Consejería de Cultura de la Junta de Extremadura. Madrid, 2001. 304 p., ilust. ISBN: 84-369-3532-2.

Trata-se da publicação das actas do congresso internacional promovido pelo Museo Nacional de Arte Romano em Mérida, em Março de 2001, sobre o tema veiculado pelo título: «El Circo en Hispania Romana».

$\mathrm{Na}$ continuidade de um conjunto de outros colóquios científicos promovidos pelo mesmo Museu e que se dedicaram ao estudo e análise dos edifícios de espectáculo na Hispânia, a exemplo de El Teatro en la Hispania Romana (1982)e de El Anfiteatro en la Hispania Romana (1992), o encontro realizado em 2001 pretendia, segundo os seus organizadores, reflectir sobre as várias facetas relacionadas com o circo, no que respeita ao edifício nos seus aspectos mais estritamente arquitectónicos e lúdicos e, ainda, nas suas expressões iconográfica, social e política.

A obra inicia-se com uma apresentação do Circo Máximo, em Roma, e do Circo de Maxêncio, uma vez que se pretendia fazer um paralelo entre lugares de espectáculo deste tipo construídos em Itália e na Hispânia.

Paola Ciancio Rossetto dedica-se ao Circo Máximo de Roma, enquanto modelo arquitectónico dos circos em período romano, pois a construção monumentalizada do período de Trajano vai contribuir, de forma paradigmática, para consumar a ruptura com a tradição do hipódromo grego de estrutura mais simples ou mesmo efémera. Essa ruptura vinha, aliás, a ser já feita desde o século I a. C. através da construção de vários tipos de edifícios dedicados a corridas de cavalos.

Contudo, mais do que as implicações arquitectónicas que possa ter, a edificação de um lugar de espectáculo com as características monumentais do Circo Máximo reflecte aspectos políticos e ideológicos relacionados com o culto imperial e com a sua exaltação através da realização dos ludi circenses. Reedificado num local já historicamente usado para corridas de cavalos, junto ao Palatino, passa a estar preparado para uma utilização polivalente, ou seja, podem aí decorrer outros tipos de manifestações lúdicas e comemorativas, como as procissões triunfais.

Por seu lado, o artigo de Giuseppina Pisani Sartorio dá-nos conta da construção mais tardia, nos arredores de Roma, de um outro edifício paradigmático: o 
circo de Maxêncio, edificado no século IV, e que fazia parte da residência imperial, ou seja, de uma estrutura de tipo privado, a exemplo de outras que se desenvolveram por todo o Império.

Tendo em atenção que Roma funcionou, efectivamente, como modelo para as edificações análogas das províncias e uma vez que o circo de Maxêncio é um dos edifícios conhecidos mais bem conservado, a sua construção permite, pois, considerá-lo como uma espécie de protótipo para edificações similares.

Um dos aspectos mais curiosos do trabalho de Giuseppina Sartorio é a análise das relações ópticas que se estabelecem durante os espectáculos hípicos e que permitem o controlo efectivo da corrida a partir do palco dos juízes, do palco do imperador (aliás, o único exemplar conservado de que há conhecimento) e do editor spectaculorum.

Um outro aspecto de que nos dá conta a autora é a existência, no circo de Maxêncio, de torres nas duas extremidades da linha dos carceres, característica comum a outras construções congéneres tardo-romanas, bem como de uma meta monumentalizada com três grandes cones.

Segundo a opinião desta autora, a construção do circo de Maxêncio documenta uma alteração fundamental: enquanto que, até finais do século III, o circo funciona como estrutura destinada a toda a população de uma cidade, protagonizando o povo um papel fundamental no jogo, quase tão importante como os próprios aurigas, esta edificação, intimamente ligada à grande residência imperial, ou seja, no seu próprio perímetro, torna o imperador o maior protagonista do circo.

Ainda antes de se iniciar a apresentação de vários edifícios da Hispânia, Jean-Claude Golvin e Fabricia Fauquet dão-nos conhecimento - através de uma apurada análise iconográfica de vários mosaicos e trabalhos escultóricos onde estão representados alguns circos reconhecidos do Império - da existência de muitos tipos de estruturas honoríficas e dedicatórias (como, por exemplo, colunas e obeliscos) e, ainda, de edículas na spina. Os autores estabelecem paralelos dessas representações com alguns dos dados arqueológicos conhecidos, nomeadamente do circo de Mérida, onde admitem ter existido um obelisco na spina; do circo de Maxêncio, onde nas extremidades da spina deveria haver colunas monumentais; e do circo de Leptis Magna, onde deveria ter sido implantada uma estátua centralizada de Cíbele.

Após estas reflexões de carácter introdutório, a obra dedica-se amplamente à apresentação de várias estruturas circenses localizadas na Hispânia, no território actualmente espanhol: Colonia Patricia; Augusta Emerita; Toletum; Tarraco; Sagunto, Valentia; e dedica dois estudos aos dois únicos exemplares de que se conhecem estruturas arqueológicas localizados no espaço português: Mirobriga (Santiago do Cacém) e Olisipo.

Quase como que «para completar o panorama do mundo circense hispano», citando os coordenadores do encontro, é apresentado um conjunto de análises dedicadas à documentação iconogáfica, epigráfica e literária.

Assim, J. M. Blázquez retoma a análise iconográfica dos mosaicos circenses hispanos de Barcelona, Girona e Itálica (este apenas conhecido através de um de- 
senho de Alexandre de Laborde, e que alguns autores, como A. Grabar e S. Settis, defendem ser uma representação do circo Máximo de Roma, até tendo em atenção o valor simbólico que o mesmo adquiriu pela clara associação das corridas de cavalos à ideologia do poder imperial, pois tratava-se da evocação da perpétua vitória do imperador). Blázquez não adere completamente a esta tese. $\mathrm{O}$ autor reportase a outras interpretações que justificam a representação musiva das corridas de cavalos na Hispânia, a exemplo de López Monteagudo, que defende que os mosaicos possuem um «carácter simbólico relacionado com as ideias de vitória e boa sorte» e que deveriam comemorar corridas de cavalos oferecidas por um magistrado em Roma ou em qualquer outra cidade do Império», e que reflectem o gosto da sociedade hispana do mundo dos latifundia da Antiguidade Tardia. Blázquez socorre-se, ainda, das interpretações de K. M. D. Dunbabin, que considera haver uma interpretação simbólica do circo como representação do Universo com claras conotações astrológicas, e de Mohamed Tacoub que considera que os mosaicos hispanos não tratam, efectivamente, de uma representação do Circo Máximo.

Trinidad Nogales Basarrate e J. M. Álvarez Matínez apresentam, por seu turno, um estudo sobre a representação dos espectáculos circenses, baseando-se na análise iconográfica, simbólica e estilística de alguns artefactos provenientes de Augusta Emerita, como uma lucerna, um conjunto pictórico datado da primeira metade do século IV, quando o circo de Mérida foi sujeito a uma grande remodelação, um pavimento musivo também da mesma época, cujo tema central são os aurigas vencedores, e um outro com a mesma cronologia, onde se destaca uma cena com quadriga conduzida por uma Vitória, que exalta, segundo os autores, o triunfo do próprio dominus, neste caso Marianus.

Uma outra contribuição, assinada por José Jacobo Storch de García y Asensio, retoma a importância dos ludi circenses na época romana e a sua clara associação ao calendário religioso. Em termos gerais, o autor divide em três grandes conjuntos as representações de cenas ligadas ao circo de que há conhecimento na Península Ibérica: a corrida propriamente dita, com figuração, ou não, do edifício onde se desenrola; a imagem do auriga vencedor; e a dos cavalos vencedores ou funalis.

Não podemos deixar de lamentar que esse importante contributo de Gracia y Asensio, inclusive com novas achegas sobre as representações em mosaicos, frescos e outros materiais não arquitectónicos, a ponto de se pretender constituir como que uma espécie de «inventário» dessas representações na Península Ibérica, factor pelo que inclui alguns dos mosaicos encontrados no território actualmente português, seja omisso relativamente à mais recente bibliografia dedicada ao tema, nomeadamente os trabalhos de J. Lancha sobre os mosaicos de Torre de Palma.

Uma outra comunicação de carácter geral, da autoria de J. Arce, confinada à Antiguidade Tardia, reveste-se de grande interesse, pois trata das mudanças ideológico/religiosas em Roma, com a introdução do Cristianismo, quando os espectáculos públicos e festas pagãs são interditados à comunidade cristã.

A existência de uma inscrição proveniente de Mérida dedicada a Sabinianus, um auriga cristão da Hispânia, permite ao autor fazer a resenha de algumas das 
questões que a mesma levanta, nomeadamente quanto à eficácia das normas eclesiásticas nesse território. Javier Arce aceita, a exemplo de outros autores, que a inscrição pode reflectir uma nova expressão ideológica, onde a teologia da vitória passou a celebrar os fiéis, especialmente os mártires, como verdadeiros vencedores, sendo o prémio o Paraíso, como o demonstra a integração da iconografia pagã da vitória no universo cristão, como é o caso da palma.

Ainda segundo este autor, é de estranhar a existência dessa inscrição, uma vez que, no Ocidente, como noutros pontos do Império, a decadência da vida urbana tem repercussões directas na organização dos $l u d i$, e só as grandes capitais provinciais ou as dioceses continuaram a ter possibilidades financeiras para garantir o dispêndio que os jogos implicavam. Adianta, porém, que é um facto que a presença dos «Bárbaros» na Península Ibérica pode ter produzido um mimetismo da tradição romana passível de proporcionar a continuidade dos jogos circenses.

No entanto, conclui Arce, a existência de inscrições tardias deste tipo em Mérida, bem como as reparações efectuadas no circo em pleno século IV, levam a aceitar que a cidade comemora desse modo o seu novo estatuto de diocesis.

De louvar o Museu Nacional de Arte Romano de Mérida e seus colaboradores pela realização de iniciativas com estas características, permitindo um debate alargado em torno de temas específicos. De louvar, ainda, a qualidade científica das comunicações apresentadas na obra sobre a qual nos detivémos.

Não poderia, contudo, deixar de salientar que, do meu ponto de vista, trabalhos de carácter temático com esta envergadura, cujo interesse ultrapassa a comunidade científica, deveriam possibilitar uma consulta mais rápida da bibliografia existente sobre o tema - no caso em apreço dos jogos circenses - pelo que teria sido desejável existir uma recolha bibliográfica geral, bem como um glossário que viabilizasse um melhor conhecimento da matéria a quem com ela não está tão familiarizado.

Reforçando o já anteriormente dito, e pese a participação portuguesa no encontro, gostaria de ter visto expresso em alguns dos textos agora editados um conhecimento mais aprofundado do que se publica em Portugal ou sobre a realidade arqueológica portuguesa, até porque essa expressão representaria também uma maior maturidade da nossa comunidade científica e o seu reconhecimento internacional. $\mathrm{O}$ circo de Balsa, por exemplo, apesar de conhecido apenas através de fontes epigráficas, poderia também ter sido alvo de um interesse maior.

Maria Filomena Barata

Ludi Romani (Espectáculos en Hispania Romana). Museo Nacional de Arte Romano, Mérida, 2002. 268 p.

Esta obra, a cuja edição superintendeu Trinidad Nogales Basarrate, está integrada num conjunto mais vasto de publicações, cuja finalidade foi dar a conhecer 